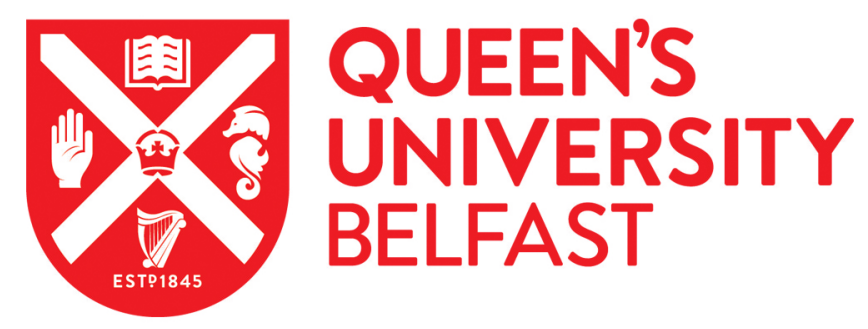

\title{
Using temporal analysis of products and flux response technology to determine diffusion coefficients in catalytic monoliths
}

Maguire, N., Sasegbon, A., Abdelkader, A., Goguet, A., Hardacre, C., Hellgardt, K., Morgan, K., \& Shekhtman, S. (2013). Using temporal analysis of products and flux response technology to determine diffusion coefficients in catalytic monoliths. Chemical Engineering Science, 87, 224-233. https://doi.org/10.1016/j.ces.2012.10.010

Published in:

Chemical Engineering Science

Document Version:

Peer reviewed version

Queen's University Belfast - Research Portal:

Link to publication record in Queen's University Belfast Research Portal

\section{Publisher rights}

This is the author's version of a work that was accepted for publication in Chemical Engineering Science. Changes resulting from the publishing process, such as peer review, editing, corrections, structural formatting, and other quality control mechanisms may not be reflected in this document. Changes may have been made to this work since it was submitted for publication. A definitive version was subsequently published in Chemical Engineering Science, VOL 87, 14/01/2012

\section{General rights}

Copyright for the publications made accessible via the Queen's University Belfast Research Portal is retained by the author(s) and / or other copyright owners and it is a condition of accessing these publications that users recognise and abide by the legal requirements associated with these rights.

Take down policy

The Research Portal is Queen's institutional repository that provides access to Queen's research output. Every effort has been made to ensure that content in the Research Portal does not infringe any person's rights, or applicable UK laws. If you discover content in the Research Portal that you believe breaches copyright or violates any law, please contact openaccess@qub.ac.uk. 


\section{Author's Accepted Manuscript}

Using Temporal Analysis of Products and Flux Response Technology to Determine Diffusion Coefficients in Catalytic Monoliths

N. Maguire, A. Sasegbon, A. Abdelkader, A Goguet, C. Hardacre, K. Hellgardt, K. Morgan, S.O. Shekhtman

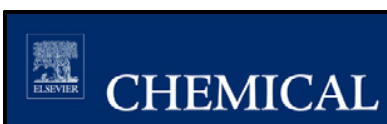

ENGINEERING SCIENCE

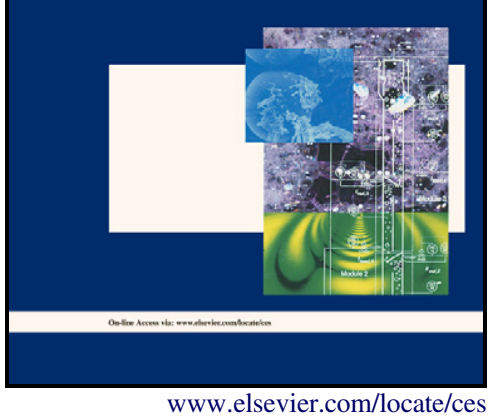

PII: S0009-2509(12)00605-7

DOI: http://dx.doi.org/10.1016/j.ces.2012.10.010

Reference: $\quad$ CES10678

To appear in: Chemical Engineering Science

Received date: 18 May 2012

Revised date: 15 September 2012

Accepted date: 7 October 2012

Cite this article as: N. Maguire, A. Sasegbon, A. Abdelkader, A Goguet, C. Hardacre, K. Hellgardt, K. Morgan and S.O. Shekhtman, Using Temporal Analysis of Products and Flux Response Technology to Determine Diffusion Coefficients in Catalytic Monoliths, Chemical Engineering Science, http://dx.doi.org/10.1016/j.ces.2012.10.010

This is a PDF file of an unedited manuscript that has been accepted for publication. As a service to our customers we are providing this early version of the manuscript. The manuscript will undergo copyediting, typesetting, and review of the resulting galley proof before it is published in its final citable form. Please note that during the production process errors may be discovered which could affect the content, and all legal disclaimers that apply to the journal pertain. 


\title{
Using Temporal Analysis of Products and Flux Response Technology to Determine Diffusion Coefficients in Catalytic Monoliths
}

\author{
N. Maguire ${ }^{1}$, A. Sasegbon ${ }^{2}$, A. Abdelkader ${ }^{1}$, A. Goguet ${ }^{1}$, C. Hardacre ${ }^{1}$, K. Kellgardt ${ }^{2}$, K. \\ Morgan $^{1}$ and S.O. Shekhtman ${ }^{1}$ \\ ${ }^{1}$ CenTACat, School of Chemistry and Chemical Engineering, \\ Queen's University Belfast, Stranmillis Road, Belfast, BT9 5AG, UK \\ ${ }^{2}$ Department of Chemical Engineering and Chemical Technology, \\ Imperial College of Science, Technology and Medicine, London, SW7 2AZ, UK
}

*Corresponding Authors: c.hardacre@qub.ac.uk; k.hellgardt@imperial.ac.uk

\begin{abstract}
The importance of accurately measuring gas diffusivity in porous materials has led to a number of methods being developed. In this study the Temporal Analysis of Products (TAP) reactor and Flux Response Technology (FRT) have been used to examine the diffusivity in the washcoat supported on cordierite monoliths. Herein, the molecular diffusion of propane within four monoliths with differently prepared alumina/ $\mathrm{CeZrO}$ washcoats was investigated as a function of temperature. Moment-based analysis of the observed TAP responses led to the calculation of the apparent intermediate gas constant, $K_{p}$, that characterizes adsorption into the mesoporous network and apparent time delay, $\tau_{a p p}$, that characterises residence time in the mesoporous network. Additionally, FRT has been successfully adapted as an extensive in situ perturbation technique in measuring intraphase diffusion coefficients in the washcoats of the same four monolith samples. The diffusion coefficients obtained by moment-based analysis of TAP responses are larger than the coefficients determined by zero length column (ZLC) analysis of flux response profiles with measured values of the same monolith samples between $20-100{ }^{\circ} \mathrm{C}$ ranging from $2-5 \times 10^{-9} \mathrm{~m}^{2} \mathrm{~s}^{-1}$ and $4-8 \times 10^{-10} \mathrm{~m}^{2} \mathrm{~s}^{-1}$, respectively. The TAP and FRT data, therefore, provide a range of the lower and upper limits of diffusivity, respectively. The reported activation energies and diffusivities clearly correlate with the difference in the washcoat structure of different monolith samples.
\end{abstract}




\section{Introduction}

Monolith supported catalysts are widely used in both the automotive industry as catalytic converters, as well as in the bulk and fine chemicals industries (Deutschen et al., 2000; Kröcker et al., 2006). Monoliths are employed to reduce external mass transfer resistance and to reduce the pressure drop over the catalyst (Zhang et al., 2004). Commonly monoliths made from cordierite or metal are used due to their high mechanical strength, although ceramic monoliths are more commonplace in catalytic converters due to their lower production costs (Degobert, 1995). The major advantage offered by metallic monoliths is the larger frontal flow area, for example a standard 400 cell $^{-2}{ }^{-2}$ mobile application cordierite is only $69 \%$ open while the metallic counterpart is $91 \%$ open (Nonnenmann, 1985; Gulati and Pierotti, 1985; Bode, 2002). In order to maintain high catalyst surface area, the active phase, e.g. a platinum group metal in the case of the automotive catalysts, is impregnated onto an oxide washcoat supported on the monolith (Taylor et al., 1980, Taylor 1984 and 1993; Oh et al., 1986; Heck et al., 1995 and 1997; Summers et al., 1994).

The ability to model the performance of monolith supported catalysts is a crucial tool required by manufacturers in order to rapidly explore alternative system designs, lower development costs and increase speed of production. Intraphase diffusion is the transport process whereby reactants/products diffuse into a porous structure that contains catalyst. Therefore, in order to accurately describe these catalytic systems, it is essential to take into account intraphase diffusion since, in most cases, it will control the transport of the reactant gases within the porous washcoat to the active sites (Zhang et al., 2004; Kolaczkowski, 2003). Hence the accurate determination of effective diffusion coefficients is imperative.

There are a number of approaches by which intraphase diffusion coefficients may be determined, the most common based upon the Wicke-Kallenbach cell (Wicke and Kallenbach, 1941; Kolaczkowski 2003; Smith 1981). This is the most simple and direct way to measure transport (macro) intraparticle diffusivity. However, this technique has many restraints and, in its original design concept, is limited to measuring pellets and cannot investigate intact monoliths. Other disadvantages associated with this approach include the need for analytical instruments downstream and the strict requirement for equal pressure in both chambers.

Since its initial conception, many modifications to the Wicke-Kallenbach system have been made which do allow the direct measurement of monoliths (Beeckman 1991; Hayes et al., 2001). However, the fundamental problem with the procedures cited is that the transport through the washcoat alone is not measured, but that the transport through both the monolith, 
e.g. cordierite, and the washcoat are measured together and the relative contributions cannot be separated. This calls into question the validity of the method in terms of the diffusion within the washcoat. The key difficulty of measuring diffusivity within a monolith washcoat is the complexity or non-homogeneity of the structure. This is particularly problematic in the case of cordierite which may contain macro-pores and/or cracks within its structure. In addition, the washcoat is a complex porous network consisting of mesopores, macropores and even macrocavities. A correct kinetic model requires transport data of how quickly molecules can enter and leave the porous washcoat containing the catalyst which is a mesoporous network rather than macrocavities. From this perspective, the residence time of the molecule within the molecule porous media is the most valuable transport information.

A number of other techniques have also been used for similar studies including the use of a zirconia oxygen sensor (which measured the difference in potential between discrete concentrations of oxygen) (Mezedur et al., 2002); a chromatographic modus operandi utilising inlet pulses of a different component injected into a packed bed of particles and the effluent pulses recorded (Santos et al., 1996); and the mounting of a section of monolith within a spinning basket to reduce the effects of gas film mass transfer (Möller et al., 1996). All these techniques rely on measuring transport through or in and out of the porous material and, therefore, provide transport or macroscopic diffusivity. In contrast, pulse field gradient NMR (PFG-NMR) has been used which measures the mean square displacement of molecules inside a porous material (Kaerger et al., 1992). The diffusivity calculated from the mean square displacement is then referred to as microscopic diffusivity. Consequently, the PFG-NMR is usually referred as a microscopic technique. This technique generally gives larger diffusivity results and lower activation energies for the diffusion while the reverse is true of the macroscopic technique (Nijhuis et al., 1997).

The purpose of this paper is to measure the intraphase diffusivity in the washcoat of monolith samples and obtain the upper and lower limits of effective diffusivity of the monoliths using Temporal Analysis of Products (TAP) (Gleaves et al., 1988), to determine the lower limit of effective diffusivity, and Flux Response Technology (FRT) (Buffham et al., 2000), to obtain the upper limit of effective diffusivity.

TAP is a fast pulse-response technique which allows the measurement of transport porous diffusivity. For most microporous and mesoporous materials, intraparticle (porous) diffusion is slow compared with the interparticle Knudsen diffusion, i.e. the main transport in the TAP reactor (Gleaves et al., 1988). Thus, porous intraparticle diffusion does not contribute to the transport through the reactor. Typically, it hinders the movement of molecules through the 
reactor in a way which is analogous to reversible adsorption (diffusion in and out of the porous material). The diffusivity of $n$-butane in zeolite silicalite- 1 has been studied with macroscopic and microscopic techniques (Nijhuis et al., 1997). The TAP results obtained were found to be in good agreement with the PFG-NMR data, although, due to the fact that curve fitting was used, the reliability of the TAP data was uncertain (Brandani and Ruthven, 2000; Nijhuis et al., 2000).

TAP has been utilised for the detailed kinetic characterization of various heterogeneous catalysts in the gas phase and has been applied to study a wide range of reactions and catalysts (Gleaves et al., 1988, 1997 and 2010; Pérez -Ramírez and Kondratenko, 2007), including diffusivity studies (Nijhuis et al., 1997 and 2000; Delgado et al., 2004; Colaris et al., 2002; van Veen et al., 2003) in a range of porous materials (Li et al., 2007). More recently, TAP has also been utilised to study intact monoliths (Gleaves et al., 2010; Kumar et al., 2009).

FRT is a powerful and versatile gas in-situ technique that is able to analyse miniscule transient flow rates in the order of $10^{-2} \mu \mathrm{L} \mathrm{min}{ }^{-1}$. The FRT method functions in a way that is analogous to an electrical Wheatstone bridge assembly whereby gas molecules represent electrons and flow capillaries represent resistors (Palmer et al., 2011). The technique is based on capillary viscometry and can be used to measure minuscule changes in flow rates between two gas streams for potentially any gaseous process involving a change in volume $(d V / d t)$ (Buffham et al., 1986 and 2002; Russell et al., 1986; Mason et al., 1998). Due to the pneumatic Wheatstone bridge configuration between the flow sensing and flow setting capillaries, FRT can make very sensitive differential measurements for a range of processes. In previous studies, the versatility of the FRT method in measuring adsorption, reaction and desorption in situ in the reactor has been reported (Buffham et al., 2000; Palmer et al., 2011; Richardson et al., 2004). By applying the Zero Length Column (ZLC) method to analyse the desorption curves generated by the FRT system, the correct representation of the rate of diffusion within the washcoat is calculated.

The control of emissions of volatile organic compounds (VOCs) such as light alkanes has become more stringent in recent years (Solsona et al., 2009). Light alkanes, such as propane, have been used extensively to examine hydrocarbon oxidation (Richardson et al., 2004) and selective catalytic reduction of $\mathrm{NO}_{\mathrm{x}}$ (Čapek et al., 2010). Hence, propane was chosen for this study as it is representative of the hydrocarbons found within exhaust gases.

\section{Materials and Methods}

Maguire et al.

To be submitted to Chem. Eng. Sci. 


\section{Samples}

The samples studied were cordierite monoliths coated with an $\mathrm{Al}_{2} \mathrm{O}_{3}-\mathrm{CeZrO}_{\mathrm{x}}$ washcoat (supplied by Johnson Matthey). Table 1 summarises the textural characteristics of the different macropore diameters determined from scanning electron microscopy.

\section{BET Surface Area Measurements}

The BET characterisation was obtained using a Tristar 3000 (Micromeritics) gas adsorption analyser using $\mathrm{N}_{2}$ to determine the specific surface area along with average pore diameter and average pore volume. The sample was subjected to vacuum to remove any impurities, such as water, followed by flushing with helium gas for $2 \mathrm{~min}$ before the vacuum was then reintroduced. The BET surface areas of each monolith sample are also summarised in Table 1.

\section{TAP Experiments}

The TAP reactor operates on the premise of injecting a small gas pulse $\left(\approx 10^{-10}\right.$ moles $)$ of very short duration $(250-500 \mu \mathrm{s})$ into an evacuated micro-reactor containing a packed bed of particles. These conditions provide the technique with a sub-millisecond time resolution. Additionally, under TAP conditions, the convective flow disappears and gas transport occurs by Knudsen diffusion.

TAP pulse experiments were performed in a TAP-1 reactor (Autoclave Engineers) using a stainless steel micro-reactor ( $41 \mathrm{~mm}$ long, $5.5 \mathrm{~mm}$ i.d.). The temperature of the reactor was measured by a thermocouple positioned in the centre of the micro-reactor, which enabled accurate temperature control via a Eurotherm 818 control unit. The probe gases were recorded at the reactor outlet by a UTI100C quadrupole mass spectrometer. Further details of the TAP system used can be found elsewhere (Goguet et al., 2006, 2011a and 2011b; Shekhtman et al., 2008; Morgan et al., 2010).

Typically, the monolith samples were prepared by cutting a small square containing 4 channels, $1 \mathrm{~mm}^{2}$ per channel, of 2-3 $\mathrm{mm}$ in length. The monolith sample was embedded between two layers of inert silicon carbide, particle size $500 \mu \mathrm{m}$ (VWR). The monoliths were studied over a range of temperatures, $20-100{ }^{\circ} \mathrm{C}$. The gas pulses employed were composed of a 1:1 ratio of krypton and propane (BOC) and all masses representative of these molecules were monitored.

\section{FRT Experiments}


The FRT method has been adapted for the measurement of gas desorption in order to perform in-situ measurements of propane desorption in the monolith samples. The experimental configuration involves the integration of a temperature programmable furnace into the Wheatstone bridge assembly. The temperature programmable furnace houses the system reactor, a quartz tube containing a fixed bed of the test sample in a well defined geometry. Samples were loaded into a quartz tube reactor ( $4 \mathrm{~mm}$ i.d.) and held in place by two plugs of quartz wool. The monolith samples were crushed and sieved to size fraction of 425-850 $\mu \mathrm{m}$.

Depending on whether the system reactor caused a pressure drop, a reference reactor was used on the reference side of the Wheatstone bridge assembly to shift the baseline of the experiment. A schematic of the experimental configuration and the expected flux response profile are presented in Figures 1 and 2, respectively.

Samples were prepared for analysis by heating in a high purity carrier stream of argon (99.99\%, BOC) from room temperature to $400{ }^{\circ} \mathrm{C}$. Samples were regenerated after each temperature cycle by heating at $400{ }^{\circ} \mathrm{C}$ for $30 \mathrm{~min}$. Typically $\sim 0.186-0.190 \mathrm{~g}$ of each monolith was used in each experiment. The sorbate used in the experiment was propane (98\%, Sigma Aldrich) and argon (99.99\%, BOC) was used as the carrier gas. The monolith samples were studied over the range of $25-100^{\circ} \mathrm{C}$. The test samples were investigated with a 1:1 ratio of argon and propane passed through the system side of the apparatus during perturbations.

The differential pressure between the system and reference flows just upstream of the measuring resistances was measured using a differential pressure transducer (Furness Controls, model FCO 44), interfaced to a data logging PC via a DataShuttle/USB 54 system (Adept scientific). Delay lines, which were lengths of empty PFA tubing (1/4 inch o.d.) were employed to delay the time at which the composition (and hence viscosity) of the gas passing through the measuring resistance changed.

\section{Theory and Analysis}

\section{TAP}

In all experiments, the thin zone TAP reactor (TZTR) concept (Shekhtman et al., 1999a) was used. Both intensity and shape of such curve can be analysed using moments, which are integrals of the observed TAP pulse responses weighted with a different power of time, as illustrated in Equation (1). 


$$
M_{n}=\int_{0}^{+\infty} t^{n} F(t) d t \quad \frac{M_{1}}{M_{0}}=\tau_{r e s}
$$

where $M_{n}$ is the moment of $\mathrm{n}^{\text {th }}$ order $\left(\right.$ mole* $\left.\mathrm{s}^{\mathrm{n}}\right), F_{\text {exit }}$ is the area-normalized exit flow $\left(\mathrm{s}^{-1}\right), M_{0}$ is the zeroth moment (mole), $M_{1}$ is the first moment (mole*s), $M_{2}$ is the second moment (mole* $\mathrm{s}^{2}$ ) and $\tau_{\text {res }}$ is the residence time of molecules (Shekhtman 2003).

$M_{0}$ determines the total number of molecules leaving the reactor after a single pulse. $M_{l}$ determines the residence time $\left(\tau_{r e s}\right)$ of a species in the micro-reactor when divided by $M_{0} . M_{2}$ determines the dispersion of residence time that can be related to the characteristic time of observed kinetic processes.

Using the moment-based analysis of the observed responses, information regarding adsorption and direct measurement of the residence time of the molecule in the porous network can be obtained (Shekhtman et al.1999b). In this analysis, the first moment, $M_{l}$, gives access to the apparent intermediate gas constant, $K_{p}$ which can be viewed as an equilibrium adsorption constant. The second moment, $M_{2}$, gives access to the apparent time delay, $\tau_{\text {app }}$, which corresponds to the residence time of the molecule inside the porous network. The detailed mathematical description of the analytical method has been reported elsewhere (Shekhtman et al., 1999a, 1999b, and 2003; Shekhtman 2003).

\section{FRT}

The governing equations used to extract information from the flux response profile are developed by understanding the flow through the sensing capillary. Theoretically, the flow can be described by the Hagen-Poiseuille Law for laminar flow. Assuming the flow through the sensing capillary is laminar, viscous and incompressible, the change in pressure $\left(p_{z}\right)$ with distance $(z)$ for the flow of fluid through a section of tube of the sensing capillary is given by Equation (2).

$$
\frac{d p_{z}}{d z}=-K_{c} \mu Q
$$

where $Q$ is the volumetric flow rate, $\mu$ is the viscosity and $K_{c}$ is a constant dependant on the characteristics of the tube.

For an ideal gas: 


$$
Q=\frac{M R T}{p_{z}}
$$

where $M$ is the molar flow rate of gas, $p_{z}$ is the pressure at distance $z, T$ is the absolute temperature and $R$ is the ideal gas constant.

By substituting for $Q$ in Equation (2) with Equation (3), the longitudinal pressure gradient can be expressed as shown in Equation (4).

$$
p_{z} \frac{d p_{z}}{d z}=-K_{c} \mu M R T
$$

The viscosity of a gas is dependant primarily on temperature. At low pressure, the viscosity is considered to be independent of pressure hence $\mu$ is constant in Equation (4) (the sensing capillaries are kept at a constant temperature). Integrating along the whole length of the capillary tube gives Equation 5.

$$
p^{2}-P_{B P R}^{2}=2 K \mu M R T
$$

where $K=K_{c} L, L$ is the length of the capillary tube, $p$ is the pressure at the inlet of the capillary and $P_{B P R}$ is the outlet pressure (Mason et al., 1998).

In order to calculate the diffusivity within the washcoat of the monolith samples, it is necessary to apply the ZLC method to analyse the FRT generated desorption curves (Eic and Ruthven, 1988b). This method has been widely used to study both micropore and macropore diffusion (Eic and Ruthven, 1988b and 1989; Silva and Rodrigues, 1996; Cavalcante et al., 1997; Ruthven and Brandani, 2000; Gunadi and Brandani, 2006; Guimarães et al., 2010). The ZLC method of measuring intraphase diffusivity depends on following the desorption of the sorbate from a previously equilibrated sample of adsorbent into an inert carrier stream. In this study, the experimental desorption curves were interpreted according to the original simplified model where the analysis utilizes the long time region of the desorption curve (Eic and Ruthven, 1988b). ${ }^{\mathbf{5 4}}$

The ZLC method is based on the following assumptions: spherical adsorbent particles, Fickian diffusion, linear sorption isotherm, perfect mixing through the cell, isothermal conditions, high flow rate of the gas stream and neglect of fluid phase hold-up. From these 
assumptions, the response curve is given by Equation (6) (Crank 1997).

$$
\frac{c}{c_{0}}=2 L \sum_{n=1}^{\infty} \frac{\exp \left(-\frac{\beta_{n}^{2} D t}{r^{2}}\right)}{\beta_{n}^{2}+L(L-1)}
$$

where $\beta_{n}$ is given by:

$$
\beta_{n} \cot \beta_{n}+L-1=0
$$

and

$$
L=\frac{1}{3} \frac{F r^{2}}{K V_{s} D}
$$

In equations 6 to $8, c$ represents the concentration at any time $t, c_{0}$ is the initial concentration, $F$ signifies the purge flow rate $\left(\mathrm{ml} \mathrm{min}^{-1}\right), V_{s}$ is the crystal volume in the ZLC cell $\left(\mathrm{cm}^{3}\right), K$ represents the dimensionless Henry's law constant, $D$ is the diffusion coefficient $\left(m^{2} s^{-1}\right), r$ is the particle radius $(\mathrm{cm})$, while $L$ and $\beta_{n}$ are dimensionless parameters. For large values of $t$, i.e. when measuring the tail of the desorption curve, only the first root of Equation (6) contributes to the summation, thereby reducing to a simple exponential decay curve shown in Equation (9) (Eic and Ruthven, 1988a). This solution has a linear asymptote in the long time region, from which the slope and intercept of plotting $\ln \left(c / c_{0}\right)$ against $t$ provide ZLC parameters, $D$ and $L$.

$$
\frac{c}{c_{0}}=\frac{2 L}{\beta_{n}^{2}+L(L-1)} \exp \left(-\frac{\beta_{n}^{2} D t}{r^{2}}\right)
$$

A plot of $\ln \left(c / c_{0}\right)$ against $t$ should give a linear asymptote in the long time region from which the slope and intercept can be used to calculate parameters $D$ and $L$. 


\section{Results and Discussion}

\section{TAP}

Preliminary TAP data showed that porous molecular diffusion could not be studied above $100{ }^{\circ} \mathrm{C}$ because the residence time within the porous washcoat network was too short compared with the residence time of molecules in the TAP reactor. Consequently, the temperature range of this study was limited to between $20-100{ }^{\circ} \mathrm{C}$ where the residence time in the porous monolith network was sufficiently long to be observed within the range of 0.05 $0.2 \mathrm{~s}$. Figure 3 shows a typical pulse response obtained over monolith Sample 1 at $60{ }^{\circ} \mathrm{C}$ (analogous pulse responses for Samples 2 to 4 are shown in the supporting information, Figures S1 to S3). ${ }^{\dagger}$

Values of $K_{p}$ and $\tau_{a p p}$ for the four monolith samples were obtained from TAP studies. Figures 4 and 5 show these calculated values of $K_{p}$ and $\tau_{a p p}$ respectively. From Figure 4 , it is clear that the $K_{p}$ values for Samples 2-4 are similar, indicating the same adsorption properties for all three samples whereas lower values were obtained for Sample 1. This difference can be explained by the fact that Sample 1 has no macroporosity (see Table 1) and, therefore, has a smaller outer surface area or specific area for entering a mesoporous network. It is also possible that the difference in the structure of the porous network and preparation methods may result in a change in the type of adsorption sites. The slopes of all curves are also comparable, irrespective of preparation method, indicating that similar adsorption sites are present for each sample. The activation energy of desorption for all the monolith samples was estimated as $30 \mathrm{~kJ} \mathrm{~mol}^{-1}$.

Figure 5 shows the temperature dependence of the residence time in the porous monolith, $\tau_{\text {app }}$, directly observed in the TAP experiment. The wide range of values for $\tau_{\text {app }}$ obtained for the four monolith samples is due to the differences in mesoporous and macroporous network structures within the washcoats. The residence time dependence characterizes the overall diffusion resistance of the material, i.e. the time period for molecules to be transported into and out of the porous network. This value may be used, without further modification, in, for example, the determination of the Thiele Modulus for the system under study. An effective diffusivity is usually associated with a relatively homogeneous porous part of the material, which, in the present case, can be considered as the washcoat. This effective diffusivity can be estimated using Equation (10). 


$$
\tau_{a p p} \approx \frac{L_{a v e}^{2}}{D_{e f f}}
$$

where $\mathrm{L}_{\text {ave }}$ is the average pore length and $\mathrm{D}_{\text {eff }}$ is the effective diffusivity.

The washcoat is a porous structure and thus can only be described by the average pore length in an approximate manner. In this case, although values for Deff may be obtained, a more representative indicator for the diffusion is $\tau_{\text {app }}$. Nevertheless, in the absence of a more accurate means of describing and measuring the average pore length of these structures, the average pore length estimates given in Table 1 were used for calculation of the porous diffusivity.

Figure 6 shows the effective diffusivities as a function of temperature for the samples measured. Clearly, an increase in the diffusivity with temperature and macropore diameter of the washcoat (given in Table 1), as expected. The parameters from the linear approximation are given in Table 2 .

\section{FRT}

Figure 7 shows an example of the flux response profile for Sample 3 (flux response profiles for Samples 1, 2 and 4 are shown in the supporting information, Figures S4 to S6). ${ }^{\dagger}$ Figure $7 \mathrm{a}$ shows an expanded view of the first dynamic cycle and highlights the partial desorption effect. Figure $7 \mathrm{~b}$ presents the entire FRT experiment showing the three dynamic cycles. As expected, a strong correlation between the expected flux response profile detailed earlier and the experimental flux response profile is apparent. The key effects are the propane partial adsorption peak, the viscosity effect caused by the propane perturbation into argon carrier gas, the propane partial desorption peak and the viscosity effect caused by the composition of the gas changing from a propane/argon mixture to purely argon carrier gas.

For the investigation of diffusivities within the washcoats of the monolith samples, it was necessary to analyse the concentration of propane in the effluent stream in order to apply the ZLC analysis. The measuring element within the FRT apparatus is an extremely sensitive differential pressure transducer (DPT) with the differential pressures measured being small relative to the absolute pressure of the system which allows the flux response signal to be linearised. The integral of the DPT pressure responses in the flux response profile have been shown to be directly proportional to the amount of probe molecules ad/desorbed onto or from the surface of the adsorbent (Richardson et al., 2008). As such, with reasonable accuracy, the 
responses by the DPT in the flux response profiles can be considered linear and directly proportional to the concentration of $\mathrm{C}_{3} \mathrm{H}_{8}$ in the effluent stream.

Figure 7 a presents the partial desorption curve that is required for the analysis of intraphase diffusivity. The analysis of the FRT partial desorption curve required this response curve to be normalized to the initial concentration by using Equation (11) (Brandini 2002):

$$
\frac{c(t)}{c_{0}}=\frac{\sigma(t)-\sigma_{\mathrm{inf}}}{\sigma_{0}-\sigma_{\mathrm{inf}}}
$$

where $\sigma_{\mathrm{n}}$ is the value of the FRT signal at time zero and $\sigma_{\text {inf }}$ is the value of the FRT signal at the completion of desorption.

The data acquisition was started at the beginning of the experiment, recording all the prevailing FRT responses to the propane perturbation before the start of the desorption curve. Consequently, in order to accurately evaluate $\sigma_{\mathrm{n}}$, the time scale from the data acquisition had to be shifted back by $t_{0}$ seconds.

Figure 8 represents the normalised experimental desorption curve for ZLC analysis. Once this curve was generated, it was necessary to account for apparatus effects influencing the measured signal response such as dispersion, dead volume and adsorption on tube walls. When the perturbation gas is switched in during the experiment, the dispersion of the probe molecules through the tubes connected to the switch in valve can have a significant role on data analysis. Such an effect can dominate the signal response as is shown in the Figure 9 and needs to be corrected for using a blank run. The trade-off between systematic errors brought about through pressure drops within the FRT apparatus and dispersion effects through the tubes of the apparatus had to be limited during the building of the FRT system and as such, such apparatus effects would have to be accounted for during data analysis. By comparing the curves of the FRT setup in the presence and absence of the test sample, it was possible to evaluate the full extent of the dispersion effect for identical system conditions. Figure 9 shows the comparison of response with the test sample and the corresponding blank.

The reason for performing the blank experiments is to use them as a comparative tool stemmed from preliminary experiments where the generated ZLC models for the FRT desorption curves fitted the long time region of the curves accurately but with seriously underestimated initial concentrations. By taking the dispersion effect into account, a better fit between the generated ZLC curves and the experimental data is attained, thus eliminating these systematic errors. 
As shown in Figure 9, the concentration ratio falls to approximately zero after $\sim 19 \mathrm{~s}$ when no sample is present while it takes $\sim 25 \mathrm{~s}$ when a sample is present. This result negates the possibility of the underestimate of initial concentrations being due simply to a slow system response time. Both experiments show a pronounced tail from $25 \mathrm{~s}$ which indicates the likely cause is due to an apparatus effect associated with dispersion through the system, as stated earlier.

Having developed a function consisting of a double exponential (Brandini 2002), it was possible to limit the influence of this dispersion by simply subtracting the difference between the models generated for the blank experiment from those with the sample present to allow the accurate application of the ZLC equations. The exponential function in Equation (12) was used to model the dispersion effect where the characteristic times, $\tau_{1}$ and $\tau_{2}$ are the characteristic times for the dispersion effect, $I$ and $I_{0}$ are the intensity at any time $\mathrm{t}$ and the maximum intensity at the start of the decay, respectively, and $t_{0}$ is an offset depending on whether the curve starts at time $=0$. Having taken the dispersion effect into account, it was then possible to evaluate the ZLC parameters, $D$ and $L$ from Equation (6). By generating a plot of $\ln \left(c / c_{0}\right)$ against $t$, it was possible to calculate these parameters by using the slope and intercept of the linear asymptote in the long time region. This is known as the long time (LT) analysis in ZLC studies (Brandini 2002):

$$
I=I_{0} e^{\left(\frac{t_{0}-t}{\tau_{1}}\right)}+\left(1-I_{0}\right) e^{\left(\frac{t_{0}-t}{\tau_{2}}\right)}
$$

The slope and intercept of the semi-logarithmic plot of $\mathrm{c} / \mathrm{c} 0$ against $\mathrm{t}$ are given, according to Equation (9), by Equation (13):

$$
S=\frac{\beta_{1}^{2} D}{r^{2}} ; I=\frac{2 L}{\beta_{1}^{2}+L(L-1)}
$$

By combining the intercept and transcendental equation (Equation (7)), the root of transcendental equation $\beta_{1}$ was found using Equation (14).

$$
\begin{aligned}
& \beta_{1}-\cot \beta_{1}+\beta_{1} \cot ^{2} \beta_{1}+\frac{2 \beta_{1} \cot \beta_{1}-2}{\beta_{1} \text { Intercept }}=0 \\
& \beta_{1} \in(0, \pi)
\end{aligned}
$$


Equation (13) was solved analytically using Maple software, from which the value of the time constant, $D / r^{2}$ and hence the diffusion coefficient could be solved (see supporting information for the full Maple code) ${ }^{\dagger}$

One of the advantages of the ZLC experimental method is that, for any particular system, the validity of the basic assumptions under the experimental conditions can be verified directly by a series of simple experiments. In performing the three cycles required for the complete FRT-ZLC experiment and comparing their asymptotes, a test for the validity of the ZLC assumptions is coincidentally carried out. Similar tests have been performed by varying the flow rate of the purge gas and comparing the long time asymptotes. In such cases, the generated asymptotes would be expected to be parallel to one another (Loos, 2000; Gunadi and Brandani, 2006; Gobin 2006).

Having evaluated the ZLC parameters from the LT analytical solutions, it was possible to construct the FRT-ZLC plots with the experimental desorption curves fitted with the ZLC model. Figure 10 is an example of the experimental curve with its appropriate model. The supporting information shows the analogous data for Samples 1, 2 and 4 (Figures S7 to S9). ${ }^{\dagger}$

It is clear from Figure 10 that good agreement exists between the experimental curve and the LT model for ZLC diffusion. Figure 11 shows the experimental and theoretical curves for the complete cycles of propane diffusion for Sample 3 as a function of temperature. The supporting information shows further temperature points for Sample 3 (Figure S10) ${ }^{\dagger}$ as well as the analogous data for Samples 1, 2 and 4 (Figures S11 to S13)..$^{\dagger}$ Again good agreement is found between the theoretical and experimental curves at each given temperature, therefore, confirming the validity of the experimental method and analysis.

Figure 12 summarises the variation of the diffusion coefficients with respect to temperature using the first desorption as well as the average value over three desorption cycles for each sample. Slight variations are found when comparing the diffusion coefficients using the desorption data from the 1st desorption and the average of 3 complete cycles. However, all the plots show a similar increasing linear trend for the variation of the diffusivity coefficients with respect to increasing temperature, as expected.

The FRT data compares well with other reported values for the diffusivity of propane in silicalite (Sun et al., 1996). Therein, a diffusion coefficient between 4-6 x 10-10 $\mathrm{m}^{2} \mathrm{~s}^{-1}$ was determined over the temperature range of $30-70{ }^{\circ} \mathrm{C}$ which may be compared with values of 4 $10 \times 10^{-10} \mathrm{~m}^{2} \mathrm{~s}^{-1}$ between $25-80{ }^{\circ} \mathrm{C}$ from the present study. The range of values reported in Figure 12 can be attributed to the structural difference within the washcoats of the samples. 
A comparison of the diffusion coefficients for all the samples as determined by FRT (Figure 12) shows a similar trend to that found using the TAP methodology (Figure 6). However, it is evident that the values differ by approximately an order of magnitude.

Table 3 compares the diffusion coefficients determined using both techniques. To evaluate the limits of effective diffusivity in the cordierite samples shown by both techniques, one should consider the sensitivities of the two methodologies. TAP measurements are sensitive to the slowest diffusing species, operating within the Knudsen regime, where the diffusivity is independent of the concentration. However, in the FRT-ZLC measurement of diffusivity, Fickian diffusion dominates and the transport diffusion coefficient accounts for the motion of species under the influence of a concentration gradient.

The reported activation energies and pre-exponential factors for diffusion were determined from the Arrhenius-plots given in Figure 6 and 12, in accordance with Equation (15).

$$
D_{e f f}=D^{o} e^{\frac{-E_{A}}{R T}}
$$

In Table 2, the activation energies for diffusion and pre-exponential factors determined by both methods are given for all four samples. Table 4 gives the activation energies for diffusion determined by other techniques to compare with this study. A large variation between the methods is observed dependant on whether the technique is microscopic or macroscopic in nature (Eic and Ruthven, 1988b; Heink et al., 1992; Sun et al., 1996; Karge et al., 2008). The microscopic techniques generally result in high diffusivities and low activation energies for diffusion. Conversely, the macroscopic techniques generally have high activation energies for diffusion and diffusivity values as much as two orders of magnitude lower when compared with the microscopic techniques. These changes may be associated with the macroscopic techniques observing other effects such as desorption during measurements as well as the actual diffusion of the molecules in the micropores. These additional effects have been shown to strongly influence the diffusivities observed (Crank 1979; Eic and Ruthven, 1988b and 1989; Van den Begin et al., 1989; Heink et al., 1992; Jobic et al., 1992; Hufton and Danner, 1993; Silva and Rodrigues, 1996; Sun et al., 1996; Cavalcante et al., 1997; Nijhuis et al., 1999; Loos 2000; Ruthven and Brandani 2000; Gobin 2006; Gunadi and Brandani 2006; Richardson et al., 2008; Karge et al., 2008; Guimarães et al., 2010). 


\section{Conclusions}

The TAP reactor has been successfully used to characterise diffusional transport in a complex porous structure of intact monoliths. The residence times in pores were experimentally determined and used for calculation of effective porous diffusivities using approximate values of pore lengths for four different samples. The obtained values of equilibrium adsorption constants and effective porous diffusivities correlate with the difference in macroporous structure of washcoat. FRT has also been successfully adapted for the in situ measurement of zero length column diffusion in cordierite samples. A mathematical model was developed in Maple to calculate the diffusion coefficients generated from the theoretical ZLC models derived through experimentation. The diffusion coefficients obtained are consistent with previously reported ZLC data (Gobin 2006) and compare well when evaluating the structural differences of the washcoats of each sample. The lower and upper limit of effective diffusivity have been evaluated using TAP and FRT methodologies, respectively, together with the activation energies and pre-exponential factors for the range of samples. The differences observed in the diffusivities of the TAP and FRT could be as a result of the Knudsen diffusion (TAP) being independent of concentration while Fickian diffusion (FRT) is dependent on a concentration gradient.

\section{Acknowledgements}

We acknowledge Johnson Matthey for supplying the catalysts, the EPSRC, under the CARMAC, CASTech, and FRT projects, for funding and DEL NI for a studentship (NM). 


\section{References}

Beeckman, J.W., 1991. Measurement of the effective diffusion coefficient of nitrogen monoxide through porous monolith-type ceramic catalysts. Ind. Eng. Chem. Res., 30, pp. 428-430.

H. Bode (Ed.), 2002. Materials Aspects in Automotive Catalytic Converters, Wiley/VCH, Weinheim, Germany.

Brandani, S., Ruthven, D.M., 2000. Comments on "Bridging the gap between macroscopic and NMR diffusivities”. Chem. Eng. Sci., 55, pp. 1935-1937.

Brandini, F., 2002. Development and Application of the Zero Length Column (ZLC) Technique for Measuring Adsorption Equilibria, PhD Thesis, University of Maine.

Buffham, B.A., Mason, G., Meacham, R.I., 1986. Sortpion-Effect Chromotography. J. Chromo. Sci., 24, pp. 265-269.

Buffham, B.A, Hellgardt, K., Heslop, M.J., Mason, G., 2000. Remote sensing of the flux responses of a gas-solid catalytic micro-reactor. Chem. Eng. Sci., 55, pp. 1621-1632.

Buffham, B.A., Mason, G., Heslop, M.J., Russell, P.A., 2002. Perturbation viscometry of gas mixtures: fitting a model to logarithmic viscosity gradients. Chem. Eng. Sci., 57, pp. 44934504.

Čapek, L., Dědeček, J., Sazama, P., Wichterlová, B., 2010. The decisive role of the distribution of $\mathrm{Al}$ in the framework of beta zeolites on the structure and activity of Co ion species in propane-SCR-NO ${ }_{x}$ in the presence of water vapour. J. Catal., 272, pp. 44-54.

Cavalcante Jr., C.L., Brandani, S., Ruthven, D.M., 1997. Evaluation of the main diffusion path in zeolites from ZLC desorption curves. Zeolites, 18, pp. 282-285.

Colaris, A.H.J., Hoebink, J. H. B. J., De Croon, M. H. J. M., Schouten, J. C., 2002. Intrapellet diffusivities from TAP pulse responses via moment-based analysis. AIChE Journal, 48, pp. 2587-2596.

Crank, J., 1979. The Mathematics of Diffusion, Oxford University Press, New York, USA.

Degobert, P., 1995. Automobiles and Pollution, Society of Automotive Engineers, Inc., Warrendale, PA.

Delgado, J.A., Nijhuis, T.A., Kapteijn, F., Moulijn, J.A., 2004. Determination of adsorption and diffusion parameters in zeolites through a structured approach. Chem. Eng. Sci., 59, pp. 2477-2487.

Deutschen, O., Maier, L.I., Riedel, U., Stroemman, A.H., Dibble, R.W., 2000. Hydrogen assisted catalytic combustion of methane on platinum. Catal. Today, 59, pp. 141-150. 
Eic, M. \& Ruthven, D.M., 1988a. A new experimental technique for measurement of intracrystalline diffusivity. Zeolites, 8, pp.40-45.

Eic, M., Ruthven, D.M., 1988b. Diffusion of linear paraffins and cyclohexane in NaX and 5A zeolite crystals. Zeolites, 8, pp. 472-479.

Eic, M., Ruthven, D.M., 1989. Intracrystalline Diffusion of Linear Paraffins and Benzene in Silicalite Studied by the ZLC Method. Stud. Sur. Sci. Catal., 49, pp. 897-905.

Gleaves, J.T., Ebner, J.R., Kuechler, C., 1988. Temporal Analysis of Products (TAP) - A unique catalyst evaluation system with millisecond time resolution. Catal. Rev. Sci. Eng., 30, pp. 49116.

Gleaves, J.T., Yablonskii, G.S., Phanawadee, P., Schuurman, Y., 1997. TAP-2: Interogative Kinetics Approach. App. Catal. A, 160, pp. 55-88.

Gleaves, J.T., Yablonsky, G., Zheng, X., Fushimi, R., Mills, P.L., 2010. Temporal Analysis of Products (TAP) - Recent Advances in Technology for Kinetic Analysis of Multicomponent Catalysts. J. Mol. Catal. A: Chem., 315, pp. 108-134.

Gobin, O.C., 2006. Synthesis, Diffusion and Sorption Properties, Seminar Thesis, Universit'e Lava.

Goguet, A., Shekhtman, S.O., Burch, R., Hardacre, C. Meunier, F.C., Yablonsky, G.S., 2006. Pulse-response TAP studies of the reverse water-gas shift reaction over a $\mathrm{Pt} / \mathrm{CeO}_{2}$ catalyst. J. Catal., 237, pp. 102-110.

Goguet, A., Hardacre, C., Maguire, N., Morgan, K., Shekhtman, S.O., Thompson, S.P., 2011 la. Time of Flight mass spectrometry for quantitative data analysis in fast transient studies using a Temporal Analysis of Products (TAP) Reactor. Analyst, 136, pp. 155-163.

Goguet, A., Hardacre, C., Inceesungvorn, B., Morgan, K., Shekhtman, S.O., 2011b. Correction for a possible reversible adsorption over the "inert" material. Catal. Sci. Tech., 1, pp. 760767.

Granato, M.A., Jorge, M., Vlugt, T.J.H., Carlo, M., 2010. Diffusion of propane, propylene and isobutane in 13X zeolite by molecular dynamics. Chem. Eng. Sci., 65, pp. 2656-2663.

Guimarães, A.P., Möller, A., Staudt, R., de Azevedo, D.C.S, Lucena, S.M.P, Cavalcante, C.L., 2010. Diffusion of linear paraffins in silicalite studied by the ZLC method in the presence of $\mathrm{CO}_{2}$. Adsorption, 16, pp. 29-36.

Gulati, S.T., Pierotti, M. J., 1985. Systems approach for designing cordierite ceramic converters for automotive emissions control. SAE Technical Paper Series 850130.

Gunadi, A., Brandani, S., 2006. Diffusion of linear paraffins in NaCaA studied by the ZLC method. Microporous and Mesoporous Mat., 90, pp. 278-283. 
Hayes, R.E., Kolaczkowski, S. T., Li, P. K., Awdry, S., 2000. Evaluating the effective diffusivity of methane in the washcoat of a honeycomb monolith. Appl. Catal. B, 25, pp. 93-104.

Heck, R.M., Farrauto, R.J., 1995. Catalytic Air Pollution Control: Commercial Technology, Van Nostrand Reinhold, New York, USA.

Heck, R.M., Farrauto, R.J., 1997. The automobile catalyst: Its present and future family tree. CATTECH, 2, pp. 117-124.

1.1. Heink, W., Kärger, J., Pfeifer, H., 1992. High-temperature pulsed field gradient nuclear magnetic resonance self-diffusion measurements of $n$-alkanes in MFl-type zeolites. J. Chem. Soc., Faraday Trans., 88, pp. 3505-3509.

\section{Hufton, J.R., Danner, R.P., 1993. Chromatographic study of alkanes in silicalite: Transport properties. AIChE Journal, 39, pp. 962-974.}

Jobic, H., Bee, M., Kearley, G.J., 1992. Dynamics of ethane and propane in zeolite ZSM-5 studied by quasi-elastic neutron scattering. Zeolites, 12, pp. 146-151.

Kaerger, J., Ruthven, D.M., 1992. Diffusion in Zeolites and other Microporous Solids, Wiley, New York, USA.

Karge, H.G., Weitkamp, J., Brandani, S., 2008. Adsorption and Diffusion, Springer, Berlin, Germany.

Kolaczkowski, S.T., 2003. Measurement of effective diffusivity in catalyst-coated monoliths. Catal. Today, 83, pp. 85-95.

Kröcker, O., Devadas, M., Elsener, M., Wokaun, A., Söger, N., Pfeifer, M., Demel, Y., Mussmann, L., 2006. Investigation of the selective catalytic reduction of $\mathrm{NO}$ by $\mathrm{NH}_{3}$ on $\mathrm{Fe}-$ ZSM5 monolith catalysts. Appl. Catal. B, 66, pp. 208-216.

Kumar, A., Medhekar, V., Harold, M.P., Balakotaiah, V., 2009. NO decomposition and reduction on $\mathrm{Pt} / \mathrm{Al}_{2} \mathrm{O}_{3}$ powder and monolith catalysts using the TAP reactor. App. Catal. B, 90, pp. 642-651.

Li, W., Xie, L., Gao, L., Zhao, X., Hu, R., Cheng, Y., Wang, D., 2007. The measurement of gas diffusivity in porous materials by temporal analysis of products (TAP). Catal. Today, 121, pp. 246-254.

Loos, J., 2000. Improved estimation of zeolite diffusion coefficients from zero-length column experiments. Chem. Eng. Sci., 55, pp. 51-65. 
Mason, G., Buffham, B.A., Heslop, M.J., Zhang, B., 1998. Capillary viscometry by perturbation of flow and composition. Chem. Eng. Sci., 53, pp. 2665-2674.

Mezedur, M M., Kaviany, M., Moore, W., 2002. Effect of pore structure, randomness and size on effective mass diffusivity, AIChE Journal. 48, pp. 15-24.

Möller, K.P., O’Connor, C. T., 1996. The measurement of diffusion in porous catalysts using a CSTR. Chem. Eng. Sci., 51, pp. 3403-3408.

Morgan, K., Cole, K.J., Goguet, A., Hardacre, C., Hutchings, G.J., Maguire, N., Shekhtman, S.O., Taylor, S.H., 2010. TAP Studies of $\mathrm{CO}$ oxidation over $\mathrm{CuMnO}_{\mathrm{x}}$ and $\mathrm{Au} / \mathrm{CuMnO}$ Catalysts. J. Catal., 276, pp. 38-48.

Nijhuis, T.A., van den Broeke, L.J.P., van de Graaf, J.M., Kapteijn, F., Makkee, M., Moulijn, J.A., 1997. Bridging the gap between macroscopic and NMR diffusivities. Chem. Eng. Sci., 52, pp. 3401-3404.

Nijhuis, T.A., Linders, M.J.G., Makkee, M., Kaptejn, J.A., 2000. Reply to comments on "Bridging the gap between macroscopic and NMR diffusivities". Chem. Eng. Sci., 55, pp. 1939-1943.

Nonnenmann, M., 1985. Metal supports for exhaust gas catalysts. SAE Technical Paper Series 850131.

Oh, S.H., Fisher, G.B., Carpenter, J.E., Goodman, D.W., 1986. Comparative kinetic studies of $\mathrm{CO}---\mathrm{O}_{2}$ and $\mathrm{CO}---\mathrm{NO}$ reactions over single crystal and supported rhodium catalysts. $\mathrm{J}$. Catal., 100, pp. 360-376.

Palmer, C., Sasegbon, A. \& Hellgardt, Klaus, 2011. In situ measurement of gas adsorption processes using Flux Response Technology. Adsorption, 17, pp. 783-794.

Pérez -Ramírez, J., Kondratenko, E.V., 2007. Evolution, achievements, and perspectives of the TAP technique. Catal. Today, 121, pp. 160-169.

Richardson, D.J., Hellgardt, K., Russell, P.A., Mason, G., Buffham, B.A., 2004. A Study of Ammonia Decomposition Over Pt / Alumina Preparation of Catalyst. Chem. Eng. Res. Des., 82, pp. 1397-1403.

Richardson, D.J., Mason, G., Buffham, B.A., Hellgardt, K., Cumming, I.W., Russell, P.A., 2008. Viscosity of Binary Mixtures of Carbon Monoxide and Helium. J. Chem. Eng. Data, 53, pp. 303-306.

Russell, P.A., Buffham, B.A., Mason, G., Heslop, M.J., 2003. Perturbation viscometer to measure the viscosity gradients of gas mixtures. AIChE Journal, 49, pp. 1986-1994.

Ruthven, D.M., Brandani, S., 2000. Measurement of diffusion in porous solids by zero length column (ZLC) methods. Mem. Sci. Tech., 6, pp. 187-212. 
Santos, A., Bahamonde, A., Avila., P., Garcia-Ochoa, F., 1996. Measurement of the effective diffusivity for a vanadia-tungsta-titania/sepiolite catalyst for SCR of NOx. App. Catal. B, 8, pp. 299-314.

Shekhtman, S.O., Yablonsky, G.S., Gleaves, J.T., Chen, S., 1999a. Thin-zone TAP reactortheory and application. Chem. Eng. Sci., 54, pp. 4371-4378.

Shekhtman, S.O., Yablonsky, G.S., Gleaves, J.T., 1999b. “A New Method for Determining Gas Diffusivities in the Complex Porous Media Using TAP Pulse Response Experiment". Proceedings of the 16th Meeting of the North American Catalysis Society, Boston, PII-093A.

Shekhtman, S.O., Yablonsky, G.S., Gleaves, J.T., Fushimi, R., 2003. "State defining" experiment in chemical kinetics-primary characterization of catalyst activity in a TAP experiment. Chem. Eng. Sci., 58, pp. 4843-4859.

Shekhtman, S.O., 2003. Interrogative kinetics: A new methodology for catalyst characterization. $\mathrm{PhD}$ thesis, Washington University, St. Louis.

Shekhtman, S.O., Goguet, A., Burch, R., Hardacre, C., Maguire, N., 2008. CO multipulse TAP studies of $2 \% \mathrm{Pt} / \mathrm{CeO} 2$ catalyst: Influence of catalyst pretreatment and temperature on the number of active sites observed. J. Catal., 253, pp. 303-311.

Silva, J., 1996. Analysis of ZLC technique for diffusivity measurements in bidisperse porous adsorbent pellets. Gas Sep. Pur., 1996, 10, pp. 207-224.

Smith, J. M., 1981. Chemical Engineering Kinetics, $3^{\text {rd }}$ edition McGraw-Hill, New York, USA.

Solsona, B., García, T., Hutchings, G.J., Taylor, S.H., Makkee, M., 2009. TAP reactor study of the deep oxidation of propane using cobalt oxide and gold-containing cobalt oxide catalysts. App. Catal. A, 365, pp. 222-230.

Summers, J.C., Williamson, W.B., 1994. Palladium-only Catalysts for Closed-loop Control, in: Armor, J.N. (Ed.), Environmental Catalysis, American Chemical Society, Washington DC, USA.

Sun, M.S., Talu, O., Shah, D.B., 1996. Diffusion measurements through embedded zeolite crystals. AIChE Journal, 42, pp. 3001-3007.

Taylor, K.C., Schlatter, J.C., 1980. Selective reduction of nitric oxide over noble metals. J. Catal. 63, pp. 53-71.

Taylor, K.C., 1984. Automobile Catalytic Converters, in: Anderson, J.R., Boudart, M., (Eds.), Catalysis-Science and Technology, Springer, Berlin, Germany.

Taylor, K.C., 1993. Nitric oxide catalysis in automotive exhaust systems. Catal. Rev. Sci. Eng. 35, pp. 457-481. 
Van-Den-Begin, N., Rees, L.V.C., Caro, J., Bülow, M., 1989. Fast adsorption-desorption kinetics of hydrocarbons in silicalite-1 by the single-step frequency response method. Zeolites, 9, pp. 287-292.

van Veen, A.C., Farrusseng, D., Rebeilleau, M., Decamp, T., Holzwarth, A., Schurrman, Y., Mirodatos, C., 2003. Acceleration in catalyst development by fast transient kinetic investigation. J. Catal., 216, pp. 135-143.

Wicke, E., Kallenbach, R., 1941. Die Oberflächendiffusion von Kohlendioxyd in aktiven Kohlen. Kolloid Z 97, pp. 135-151.

F Zhang, F., Hayes, R., Kolaczkowski, S., 2004. A New Technique to Measure the Effective Diffusivity in a Catalytic Monolith Washcoat. TransIChemE A, 82, pp. 481-489. 
Table 1 Textural characteristics of the blank and coated monolith samples.

\begin{tabular}{cccc} 
Sample & $\begin{array}{c}\text { Macropore } \\
\boldsymbol{\mu m}\end{array}$ & $\begin{array}{c}\text { BET } \\
\text { Surface Area } \\
\mathbf{m}^{\mathbf{2}} \mathbf{g}^{-1}\end{array}$ & $\begin{array}{c}\text { Pore Length } \\
\boldsymbol{\mu m}\end{array}$ \\
\hline Blank & - & 0.70 & - \\
monolith & & 23.79 & 21 \\
Sample 1 & - & 21.63 & 52 \\
Sample 2 & 3 & 26.79 & 47 \\
Sample 3 & 5 & 25.60 & 46 \\
Sample 4 & 10 & &
\end{tabular}

Table 2 Pre-exponential factors and activation energies of diffusion in Samples 1-4 determined using the TAP and FRT methodologies.

\begin{tabular}{ccccc} 
Sample & \multicolumn{2}{c}{$\begin{array}{c}\text { Pre-exponential } \\
\text { factor } \\
\mathbf{m}^{2} \mathbf{s}^{-1}\end{array}$} & \multicolumn{2}{c}{$\begin{array}{c}\text { Activation Energy } \\
\text { kJ mol }^{-1}\end{array}$} \\
\cline { 2 - 5 } & TAP & FRT & TAP & FRT \\
\hline Sample 1 & $1.7 \times 10^{-7}$ & $8.3 \times 10^{-9}$ & $12 \pm 0.3$ & $7 \pm 0.4$ \\
Sample 2 & $6.5 \times 10^{-7}$ & $9.5 \times 10^{-9}$ & $11 \pm 0.4$ & $7 \pm 1.6$ \\
Sample 3 & $6.6 \times 10^{-6}$ & $1.0 \times 10^{-8}$ & $14 \pm 0.4$ & $6 \pm 0.8$ \\
Sample 4 & $2.5 \times 10^{-5}$ & $1.7 \times 10^{-8}$ & $16 \pm 0.5$ & $8 \pm 0.1$ \\
\hline
\end{tabular}


Table 3 Comparison of diffusivity coefficients between TAP and FRT.

\begin{tabular}{cccc} 
& & \multicolumn{2}{c}{$\begin{array}{c}\text { Diffusivity } \\
\mathbf{m}^{2} \mathbf{s}^{-1}\end{array}$} \\
\cline { 3 - 4 } Sample & Kemp & TAP & FRT \\
\hline \multirow{3}{*}{ Sample 1 } & 313 & $2.55 \times 10^{-9}$ & $5.6 \times 10^{-10}$ \\
& 333 & $3.86 \times 10^{-9}$ & $7.2 \times 10^{-10}$ \\
& 353 & $4.80 \times 10^{-9}$ & $7.8 \times 10^{-10}$ \\
\hline \multirow{3}{*}{ Sample 2 } & 313 & $9.20 \times 10^{-9}$ & $6.4 \times 10^{-10}$ \\
& 333 & $2.12 \times 10^{-8}$ & $9.7 \times 10^{-9}$ \\
& 353 & $1.60 \times 10^{-8}$ & $1.2 \times 10^{-9}$ \\
\hline \multirow{3}{*}{ Sample 3 } & 313 & $2.28 \times 10^{-8}$ & $1.0 \times 10^{-9}$ \\
& 333 & $2.56 \times 10^{-8}$ & $1.2 \times 10^{-9}$ \\
& 353 & $3.22 \times 10^{-8}$ & $1.3 \times 10^{-9}$ \\
\hline \multirow{3}{*}{ Sample 4 } & 313 & $2.20 \times 10^{-8}$ & $7.9 \times 10^{-10}$ \\
& 333 & $4.25 \times 10^{-8}$ & $9.4 \times 10^{-10}$ \\
& 353 & $5.58 \times 10^{-8}$ & $1.2 \times 10^{-9}$
\end{tabular}

Table 4 Overview of activation energies for propane diffusion calculated using different techniques.

\begin{tabular}{|c|c|c|c|}
\hline Sorbent & $\begin{array}{c}E_{\mathrm{A}} \\
\mathrm{kJ} \mathrm{mol}^{-1}\end{array}$ & Technique & Reference \\
\hline \multirow{2}{*}{$\begin{array}{l}\text { Cordierite } \\
\text { monolith }\end{array}$} & $12-16$ & TAP & this study \\
\hline & $6-8$ & FRT-ZLC & this study \\
\hline \multirow{8}{*}{ Silicalite-1 } & 7.2 & Multitrack & Nijhuis et al., 1999 \\
\hline & 6.7 & FR & Van den Begin et al., 1989 \\
\hline & 13.0 & ZLC & Eic and Ruthven, 1989 \\
\hline & 25.6 & $\mathrm{CPC}$ & Hufton and Danner, 1993 \\
\hline & 8.0 & Wicke-Kallenbach & Sun et al., 1996 \\
\hline & 5.0 & $\mathrm{QENS}^{\mathrm{a}}$ & Jobic et al., 1992 \\
\hline & 6.0 & PFG-NMR ${ }^{\mathrm{a}}$ & Heink et al., 1992 \\
\hline & 7.9 & MD simulations & Granato et al., 2010 \\
\hline
\end{tabular}


Figure 1 Schematic of the FRT experimental setup.

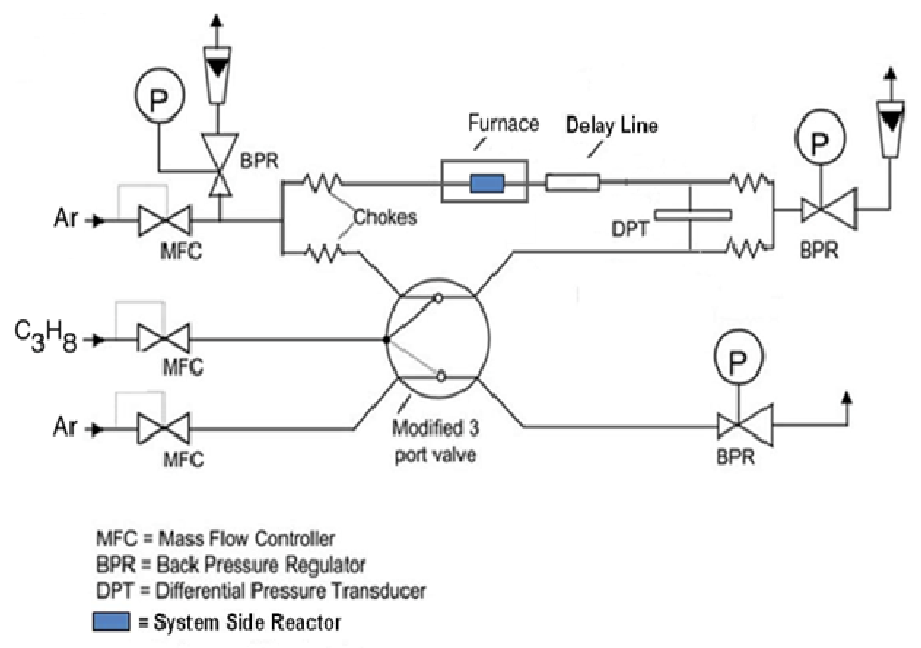

Figure 2 Schematic of expected flux response profile for $\mathrm{C}_{3} \mathrm{H}_{8}$ sorption under isothermal conditions for varying molar fractions of $\mathrm{C}_{3} \mathrm{H}_{8}$ perturbation gas in an Ar carrier gas illustrated by $\mathrm{P}_{1} / \mathrm{P}_{0}, \mathrm{P}_{2} / \mathrm{P}_{0}, \mathrm{P}_{3} / \mathrm{P}_{0}$.

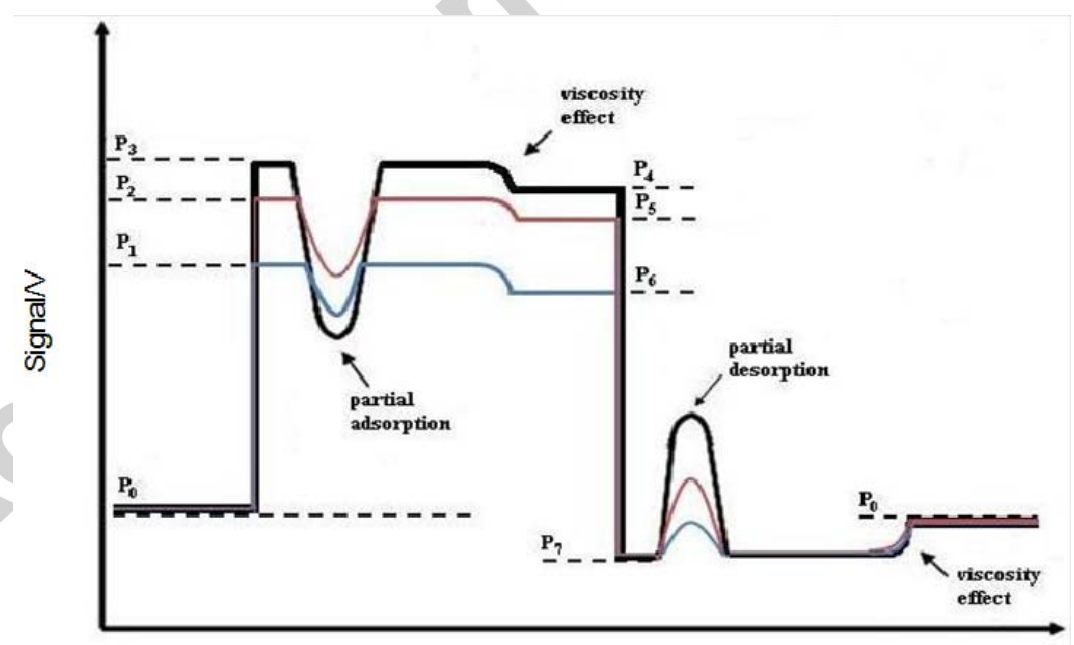

Timeis 
Figure 3 TAP pulse responses and theoretical fits (solid lines) of krypton (•) and propane ( $\bullet$ ) for Sample 1 at $60^{\circ} \mathrm{C}$.

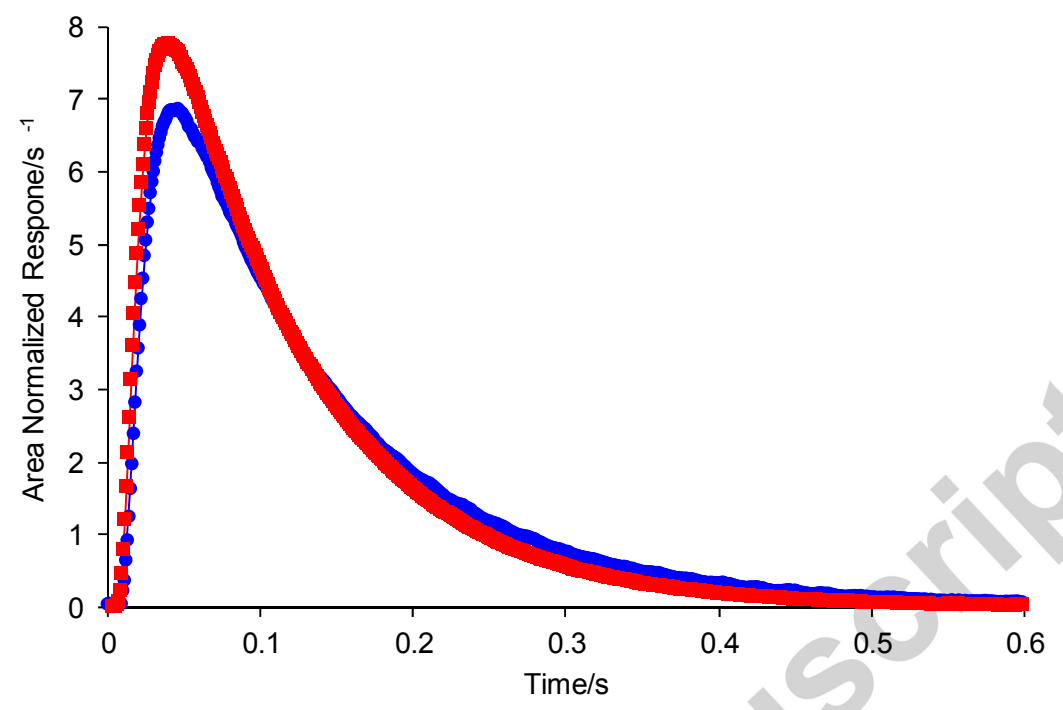

Figure 4 Variation of $\ln \left(K_{p}\right)$ as a function of temperature for Sample $1(\mathbf{\square})$, Sample $2(\diamond)$, Sample $3(\mathbf{\Delta})$ and Sample $4(\bullet)$, derived from TAP.

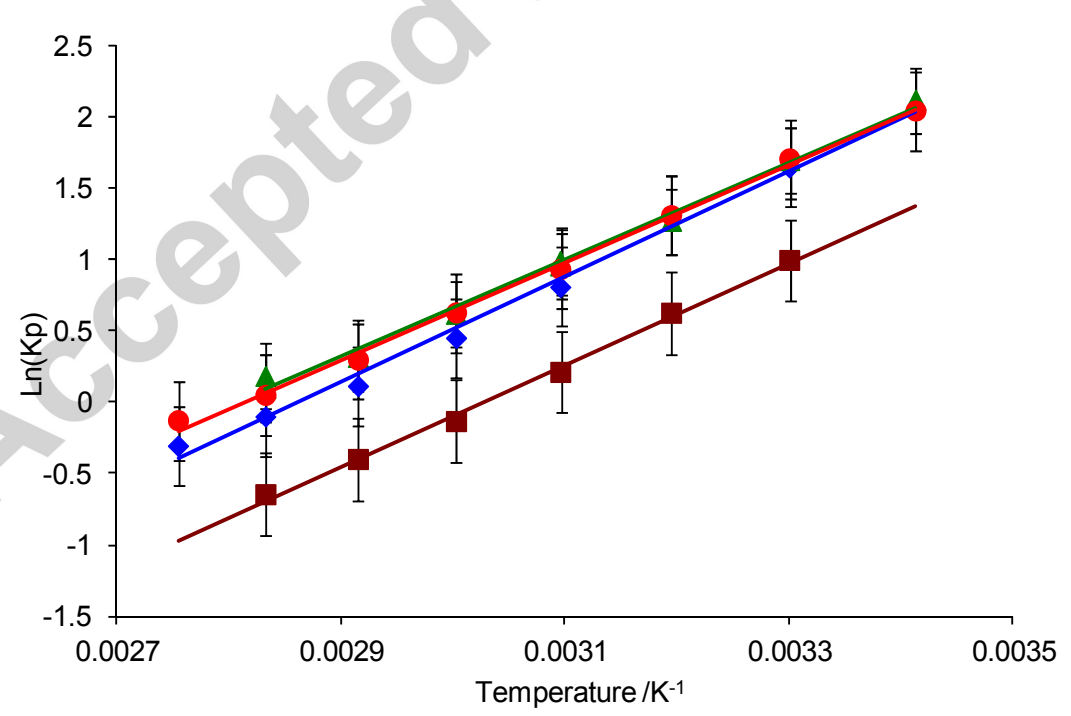


Figure 5 Variation of $\ln \left(\tau_{\text {app }}\right)$ as a function of temperature for Sample $1(\boldsymbol{\square})$, Sample $2(\bullet)$, Sample $3(\boldsymbol{\Delta})$ and Sample $4(\bullet)$, derived from TAP.

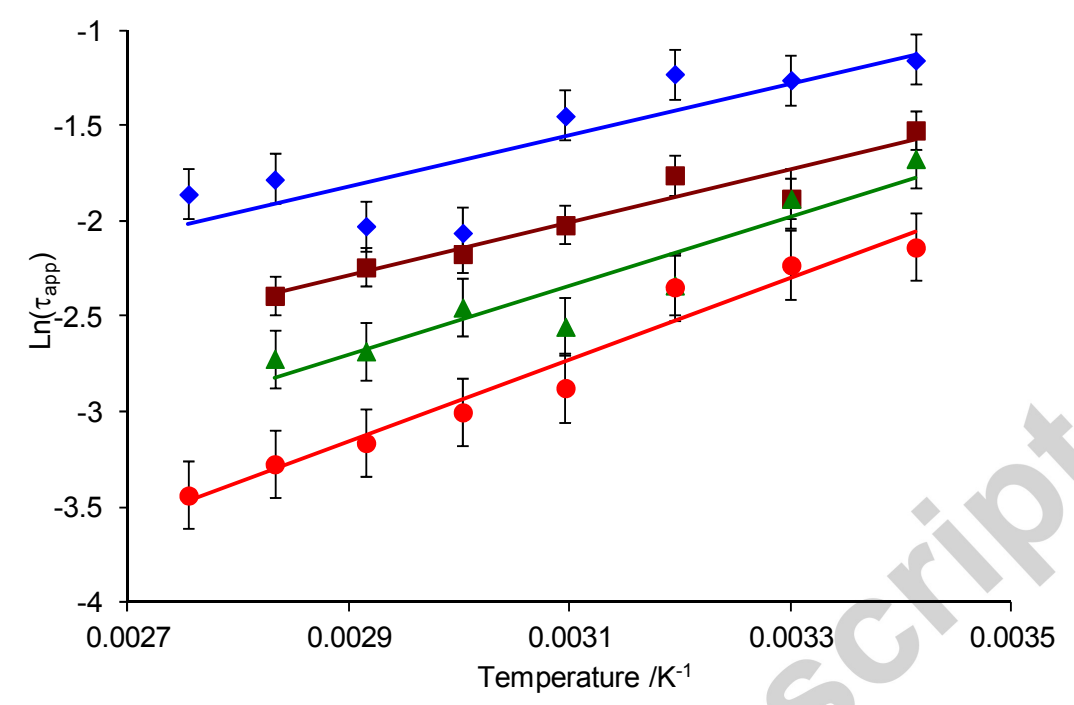

Figure 6 Variation of $\ln \left(D_{\text {eff }}\right)$ with temperature for Sample $1(\mathbf{\square})$, Sample $2(\diamond)$, Sample 3 $(\boldsymbol{\Delta})$ and Sample $4(\bullet)$, derived from TAP.

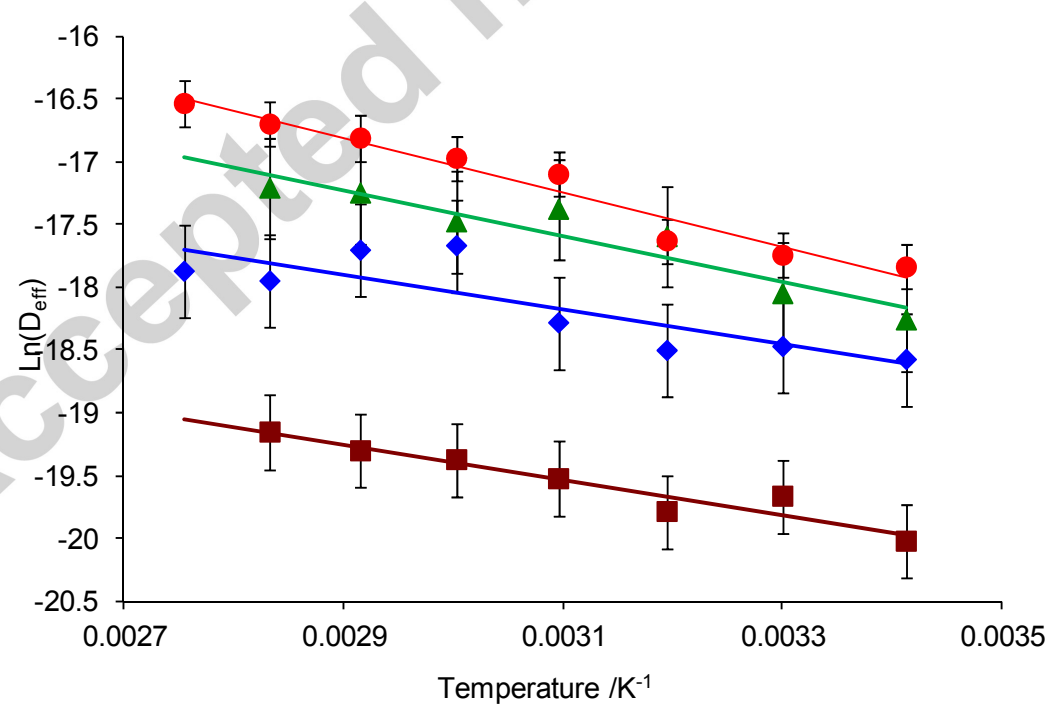


Figure 7 Flux response profile for Sample 3 using propane (mole fraction $=0.5$ ) for (a) first sorption cycle showing partial desorption and (b) the complete experiment showing three sorption cycles.

(a)
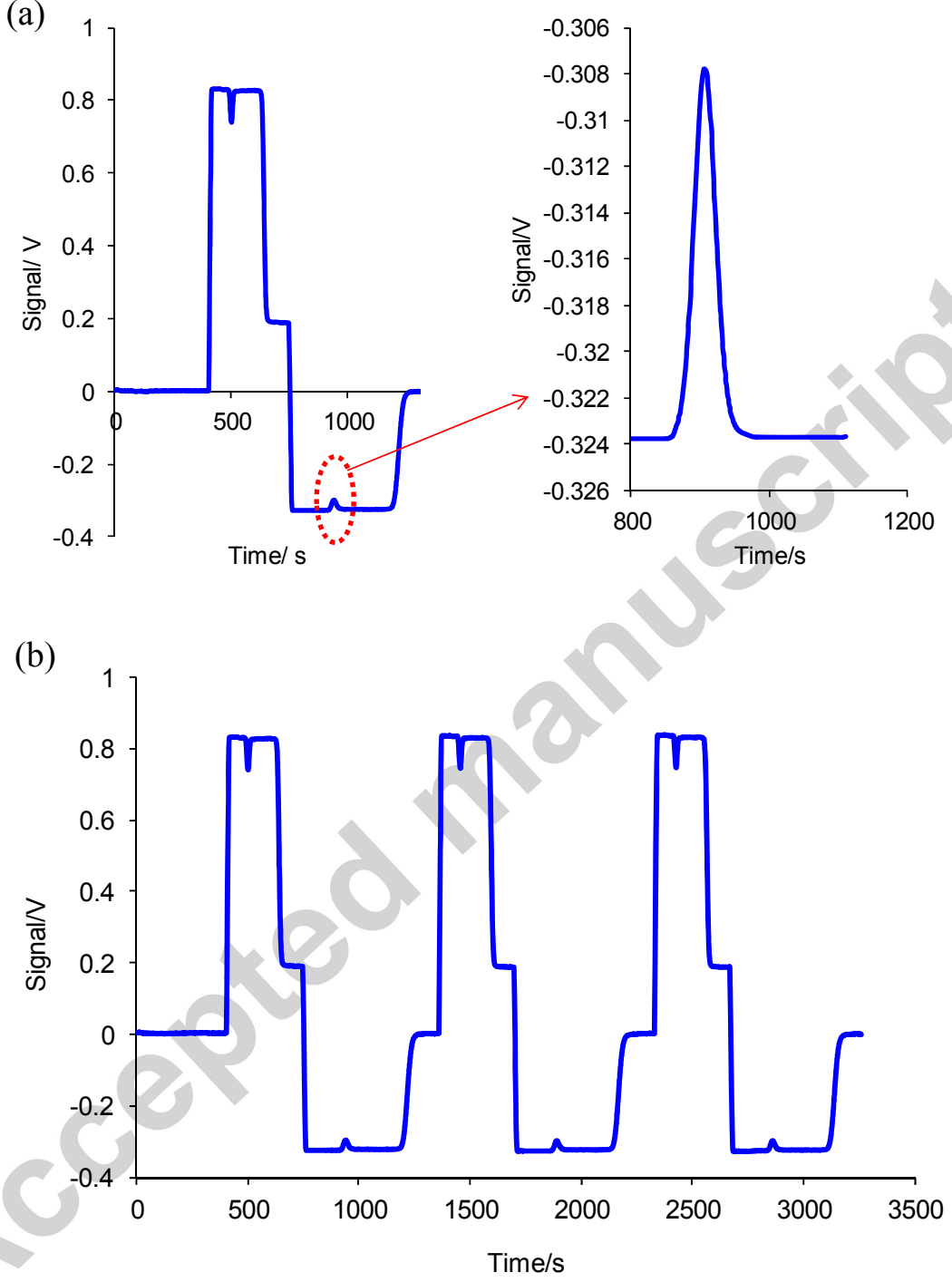

Maguire et al.

To be submitted to Chem. Eng. Sci. 
Figure 8 Experimental FRT-ZLC for the $1^{\text {st }}$ desorption curve using propane (mole fraction $=$ $0.5)$ at $25^{\circ} \mathrm{C}$.

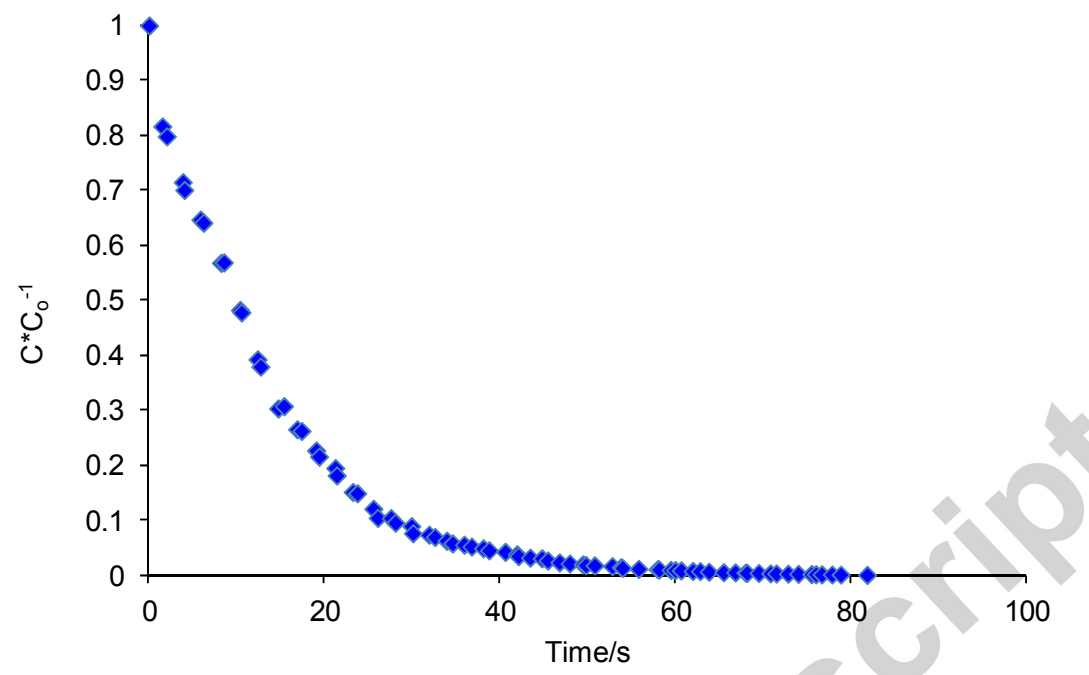

Figure 9 Comparison of the FRT-ZLC curves measured for system in the presence and absence of Sample 3 at $25^{\circ} \mathrm{C}$ (propane mole fraction, 0.5 ).

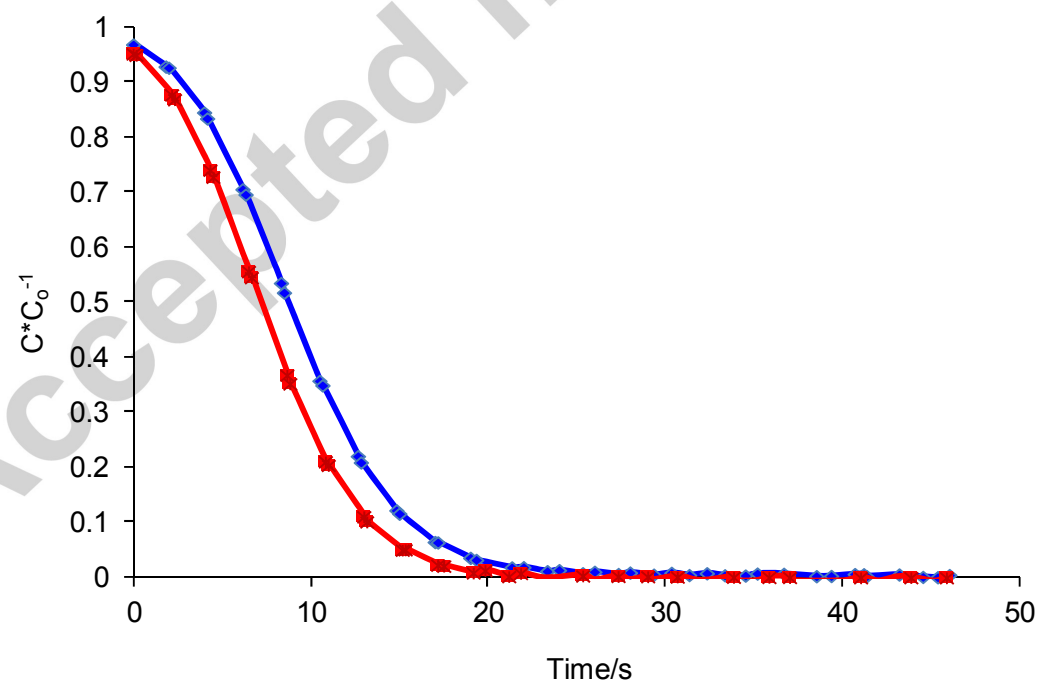


Figure 10 FRT Experimental (points) and fitted (solid line) curves for Sample 3 using propane (mole fraction $=0.5)$ at $40{ }^{\circ} \mathrm{C}$.

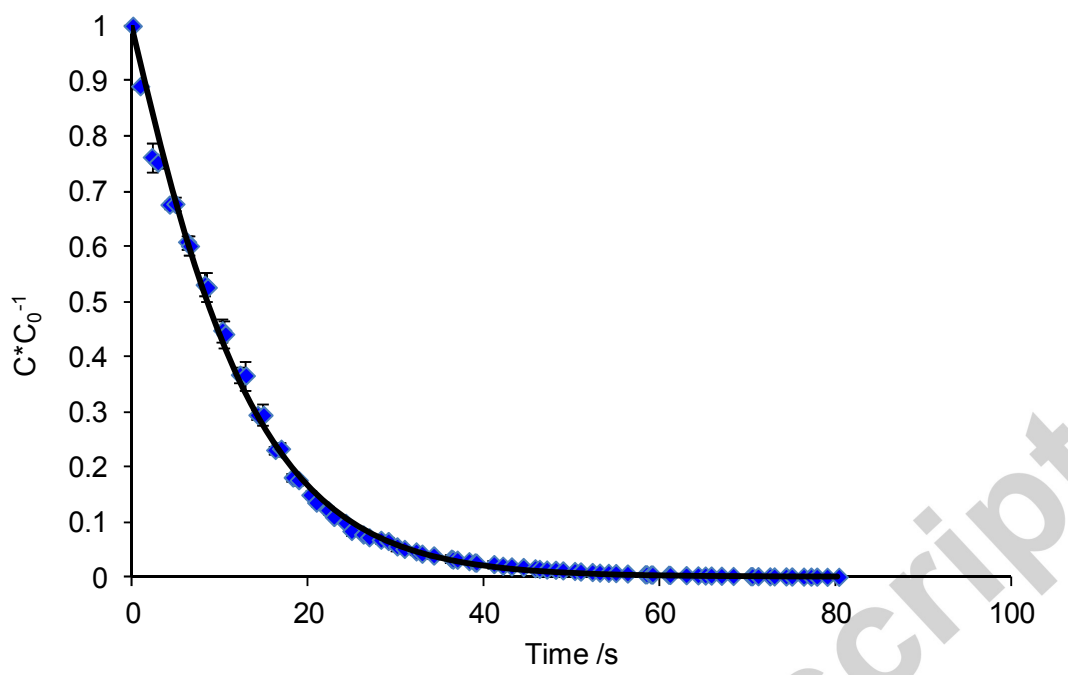

Figure 11 Complete cycle of FRT experimental $\left(1^{\text {st }}\right.$ cycle $(\diamond), 2^{\text {nd }}$ cycle $(\mathbf{\Delta}), 3^{\text {rd }}$ cycle $\left.(X)\right)$ and fitted (solid lines) desorption curves for Sample 3 using propane (mole fraction of 0.5) at $25{ }^{\circ} \mathrm{C}$.

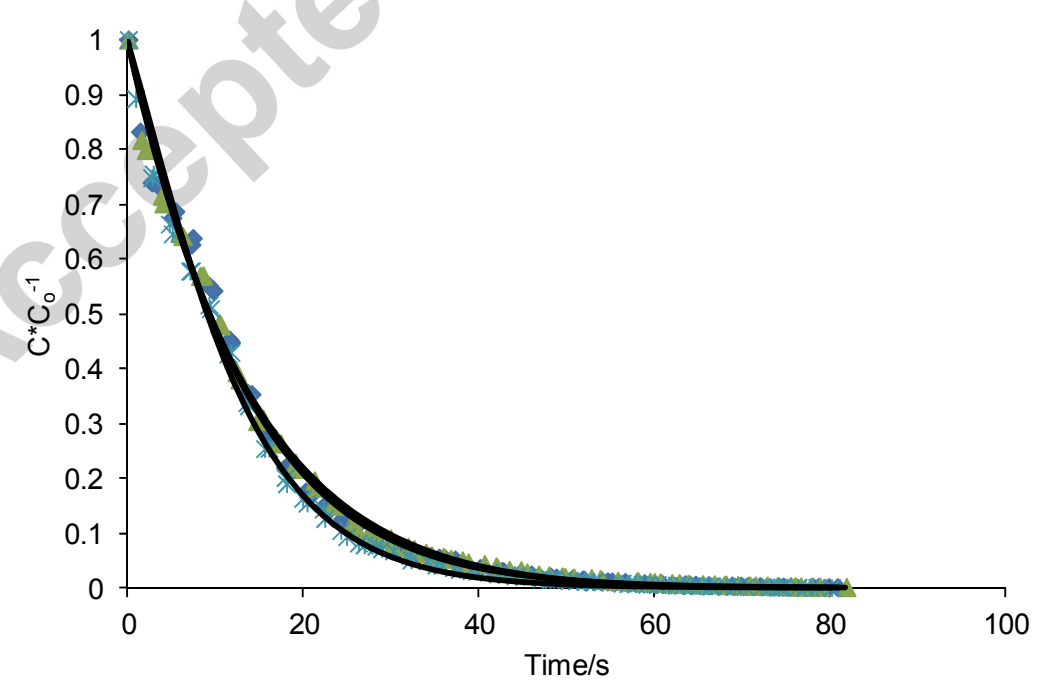


Figure 12 FRT Diffusion coefficients at temperatures between $25{ }^{\circ} \mathrm{C}-100{ }^{\circ} \mathrm{C}$ for (a) $1^{\text {st }}$ desorption cycle and (b) averaged desorption cycles, showing Sample 1(ロ), Sample 2 $(\bullet)$,Sample $3(\boldsymbol{\Delta})$, and Sample 4(•).

(a)

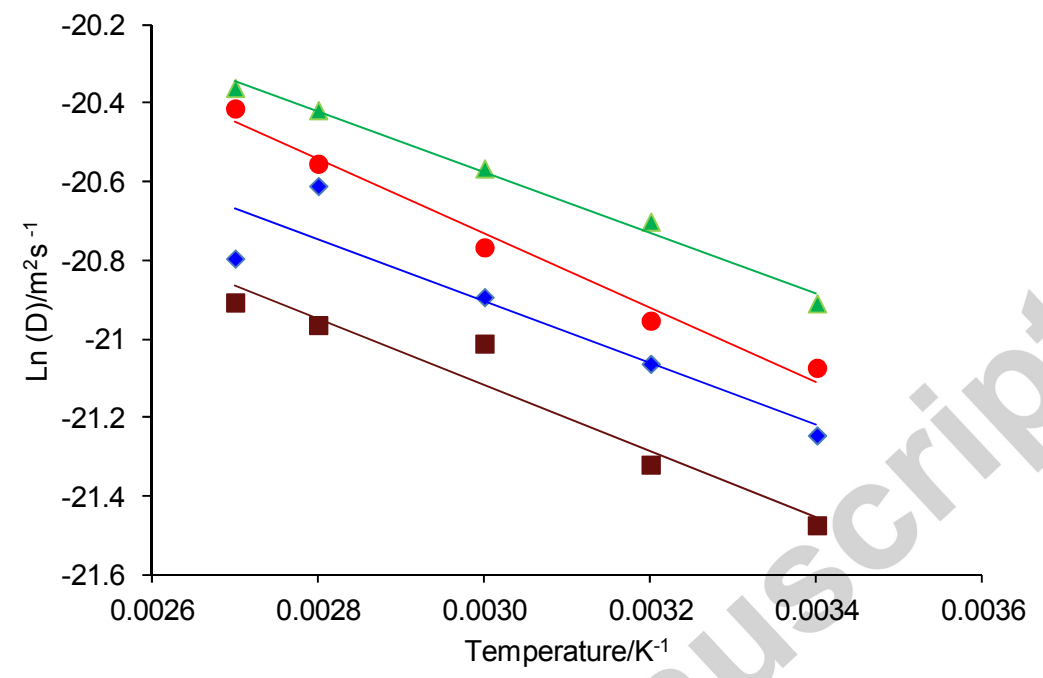

(b)

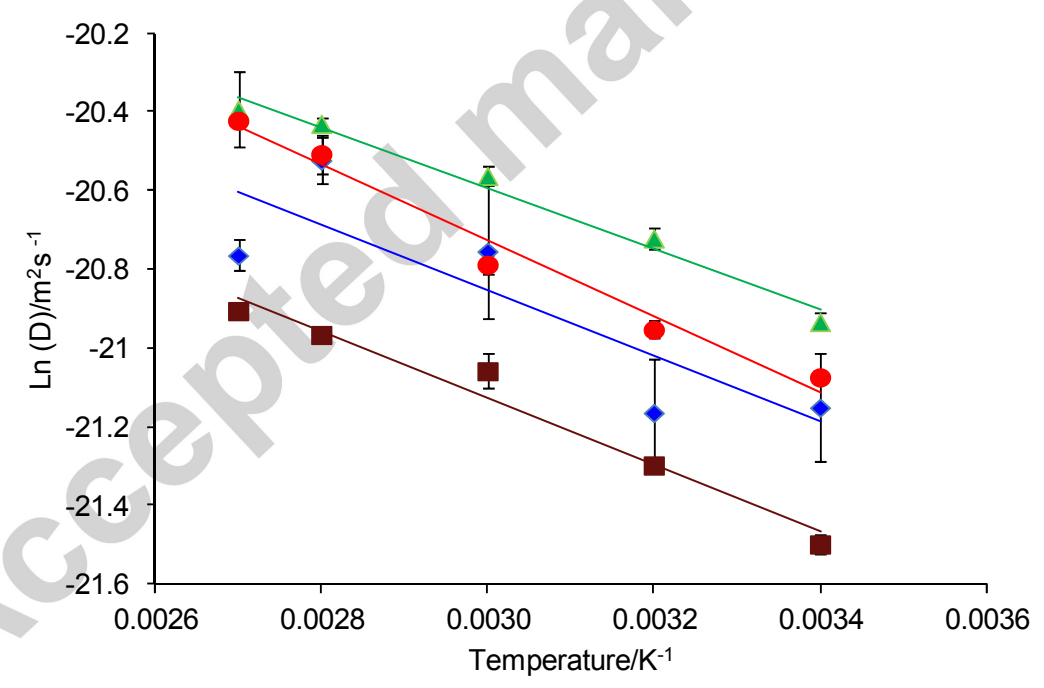




\section{Highlights}

Gas diffusivity in porous materials has been measured using TAP and FRT technologies

Molecular diffusion of gases has been measured in monolith supported catalysts

TAP and FRT data provide the lower and upper limits of diffusivity, respectively

The activation energies and diffusivities correlate with the washcoat structure 